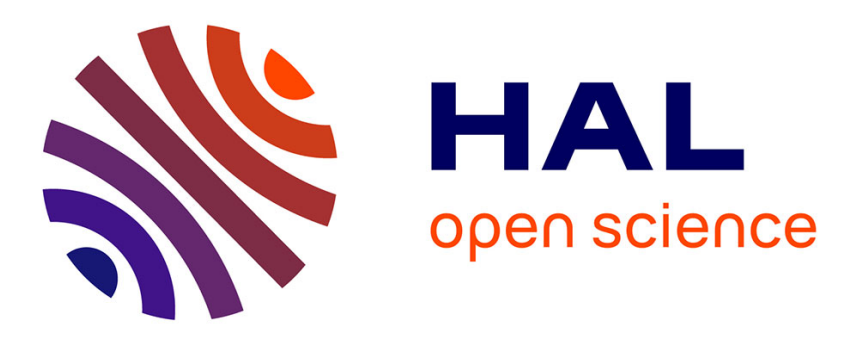

\title{
A Conformal Ultrawideband Antenna with Monopole-Like Radiation Patterns
}

\author{
Bahare Mohamadzade, Roy B. V. B. Simorangkir, Raheel M. Hashmi, Ali
}

Lalbakhsh

\section{- To cite this version:}

Bahare Mohamadzade, Roy B. V. B. Simorangkir, Raheel M. Hashmi, Ali Lalbakhsh. A Conformal Ultrawideband Antenna with Monopole-Like Radiation Patterns. IEEE Transactions on Antennas and Propagation, 2020, 68 (8), pp.6383-6388. 10.1109/TAP.2020.2969744 . hal-02651095

\section{HAL Id: hal-02651095 \\ https://hal-univ-rennes1.archives-ouvertes.fr/hal-02651095}

Submitted on 12 Jun 2020

HAL is a multi-disciplinary open access archive for the deposit and dissemination of scientific research documents, whether they are published or not. The documents may come from teaching and research institutions in France or abroad, or from public or private research centers.
L'archive ouverte pluridisciplinaire HAL, est destinée au dépôt et à la diffusion de documents scientifiques de niveau recherche, publiés ou non, émanant des établissements d'enseignement et de recherche français ou étrangers, des laboratoires publics ou privés. 


\title{
Communication A Conformal Ultrawideband Antenna with Monopole-Like Radiation Patterns
}

\author{
Bahare Mohamadzade, Roy B. V. B. Simorangkir, Raheel M. Hashmi, and Ali Lalbakhsh
}

\begin{abstract}
A simple conformal ultrawideband (UWB) antenna with monopole-like radiation patterns is proposed in this communication. To achieve the wide bandwidth, two rings are arranged concentrically around the main annular-ring circular patch antenna, in which two rectangular slots are added. The antenna has monopole-like radiation patterns generated by combining four propagation modes of $\mathbf{T} \mathbf{M}_{01}, \mathbf{T} \mathbf{M}_{02}, \mathbf{T} \mathbf{M}_{03}$, and $\mathbf{T} \mathbf{M}_{04}$ throughout the operating bands. To enhance the flexibility and robustness, the proposed antenna is fabricated using conductive fabric embedded into polydimethylsiloxane (PDMS) polymer. To our knowledge, this is the first flexible UWB antenna with monopole-like radiation patterns reported in the open literature. The measured results show that the antenna achieves a $10 \mathrm{~dB}$ return loss bandwidth from 2.85 to $8.6 \mathrm{GHz}$. Monopole-like radiation patterns are maintained throughout the frequency band, agreeing well with simulated results. This has been validated through the measured Mean Realized Gain (MRG) pattern from 2.85 to $8.6 \mathrm{GHz}$. The fabricated antenna was bent and tested at various curvatures to verify its conformability. To evaluate suitability for UWB communications, the system-fidelity factors of the antenna are investigated using full-wave analysis in CST Microwave Studio, in both flat and bent conditions, validating its potential for UWB pulse transmission.
\end{abstract}

Index Terms-Circular patch, conformal antenna, flexible antenna, monopole-like radiation pattern, ring patch, ultrawideband (UWB).

\section{INTRODUCTION}

The extensive demands in broadband wireless communication have brought attentions to the ultrawideband (UWB) technology. This is owing to its versatile features of high datarate transmission a over short distance, low power consumption, and robustness against multipath [1]. Current research efforts in this area include the development of compact UWB antennas having monopole-like radiation characteristics. Such antennas are of interest in applications that require vertical polarized waves for minimum path-loss and omnidirectional radiation characteristics for wide coverage in all directions. On top of that, due to the space limitations and the nature of the applications, having antennas that are physically small or low visual signature is generally of paramount importance. Among them are Wireless Body Area Networks (WBANs), unmanned aerial vehicles (UAVs), synthetic aperture radar (SAR), selfmanaging ground sensor networks, in-vehicle sensing and network surveillance [2]-[8].

This work was supported in part by the International Macquarie University Research Excellence Scholarship (iMQRES).

B. Mohamadzade, R. M. Hashmi, and A. Lalbakhsh are with the School of Engineering, Macquarie University, Sydney, NSW 2109, Australia (email: bahare.mohamadzade@students.mq.edu.au).

R. B. V. B. Simorangkir is with the University of Rennes 1, CNRS, Institut d'Electronique et de Télécommunications of Rennes (IETR)-UMR 6164, F35000 Rennes, France and the School of Engineering, Macquarie University, Sydney, NSW 2109, Australia (e-mail: roy.simorangkir@ieee.org).
Modified vertically-polarized electric monopole antennas over a ground plane are perhaps the most basic ways to achieve an UWB antenna with radiation characteristics mentioned above. Variations on this class of antenna have been reported in the past for achieving a considerably large bandwidth than the conventional designs, including the shape modifications of the cylindrical stub radiator [9], [10], the substitution of the cylindrical stub with planar plates with various shapes [11], [12], or the dielectric loading on monopole radiator [13]. Though the design goals have been achieved, the drawback of these approaches is that the high profile and the rigid structure associated with such antennas may not be suitable for applications requiring low profile and conformability, such as those mounted over the exterior of a vehicle or a person's body. A number of significant efforts have been therefore conducted to realize compact and low-profile UWB antennas with monopole-like radiation characteristics, utilizing various radiating elements from loops, bow tie, to monocones, with or without top-hat loadings [4], [7], [8], [14]-[18].

An UWB antenna based on magnetically-coupled two sectoral loop structures with dimension of $1.36 \lambda_{\min } \times 1.36 \lambda_{\min }$ is developed in [14]. It presents a slightly compact structure with height of $0.16 \lambda_{\min }$ yet, the height was still relatively higher for ambient applications. The same issue also can be seen in the 3-D loops design in [17] in addition to the two feeding points which add design complexity to this presented structure. Miniaturized version of [14] having a lower height of $0.053 \lambda_{\min }$ was later reported in [4]. This noticeably reduced height of the antenna was unfortunately compromised by a larger lateral area $\left(0.9 \lambda_{\min } \times 0.9 \lambda_{\min }\right)$.

Another design with a very compact dimension of $0.26 \lambda_{\min } \times 0.26 \lambda_{\min } \times 0.046 \lambda_{\min },\left(f_{\min }=0.66 \mathrm{GHz}\right)$ was presented in [16]. The design was developed from the the compact two bent-diamond structure with dimension of $0.22 \lambda_{\min } \times 0.22 \lambda_{\min } \times 0.033 \lambda_{\min }$ in [7], providing an improved consistency of the radiation patterns. The antenna requires a frequency-dependent feeding network with the help of a diplexer and a power divider, which unfortunately presents new challenges in terms of cost, weight and complexity in the structure.

Different approach utilizing various conical structures have been proposed in [8], [15], [18]. In [8], a low profile of $0.086 \lambda_{\min }$ achieved by the introduction of a small cylinder in the antenna configuration, which was then covered by a radome to protect the delicate pins. In [15], four thin shorting pins with diameter of $1 \mathrm{~mm}$ are used to short the patch on the top of monocone structure to the ground in order to generate additional resonance with the higher-order $\mathrm{TM}_{41}$ mode. In [18], directors, nylon spacers and four loops were added 
to the monocone, providing improvement in performance, and concurrently adding the complexity, thus necessitating a rigid structure with protection to delicate parts for some applications. Despite the success, all the aforementioned UWB antennas were composed of 3-D shaped structure and made of rigid materials. These characteristics present a challenge for their use in several modern wireless applications where the platforms are curved, and require a conformal antenna that is resilient to the surroundings and mechanically robust, for instance, automobile exteriors in vehicular networks, leading edge of an aircraft wing, and human body in WBANs [19][21].

In this paper, a conformal UWB antenna with monopolelike radiation patterns is presented. The antenna presents a planar and flexible structure, making it suitable for conformal applications and is compact both laterally as well as in terms of height. The proposed antenna was fabricated based on the PDMS-conductive fabric composite technique, in which all antenna parts, including radiator and ground plane are embedded inside the PDMS, making it resilient to harsh environment, and hence suitable for the applications outlined above. The radiating structure comprises of an annular-ring circular patch loaded with two rectangular slots, and two additional parasitic rings added concentrically around the annular-ring circular patch.

The presented flexible antenna is based on circular patch antenna which does not require any extra matching circuitry and offers a wide impedance bandwidth, ranging from 2.85 to 8.6 GHz. By combining multiple $\mathrm{TM}_{0 n}$ modes, the antenna bandwidth has improved considerably compared to the other reported monopolar patch antennas, e.g., wideband circular patch antenna with two coupled annular rings (5.45 to $7.16 \mathrm{GHz}, 27.1 \%$ ) [22], circular microstrip patch antenna with a coupled annular ring $(12.8 \%$ at the $5.8 \mathrm{GHz})$ [23], and circular ring patch shorted to the ground plane by four shorting posts and a coupling patch connected with a feeding (4.27 to $8.72 \mathrm{GHz}, 68.5 \%$ ) [24], whereas the structure is flexible without using any rigid pins.

The design and fabrication guidelines of the antenna are given. The characteristics of the antenna are investigated through simulations and measurements both when the antenna is in flat condition and when it is conformed over various cylindrical surface, validating its conformability. The capability for UWB pulse transmission is also evaluated through System Fidelity Factor (SFF) investigations.

\section{Proposed UWB Antenna}

\section{A. Antenna Configuration and Design Method}

The configuration of the proposed antenna is depicted in Fig. 1. The design comprises an annular-ring circular patch antenna, concentrically loaded with other two ring patches. The radiator layers, having a total radius of $r_{6}$, are printed on top of a $h_{s}$ thickness polydimethylsiloxane (PDMS) substrate. The permittivity of the PDMS is relatively constant at 2.77 with an increasing loss tangent from 0.02 to 0.076 from 2 to $10 \mathrm{GHz}$ based on the measurement conducted using Agilent 85070 E Dielectric Probe Kit. Underneath the radiator patches, there is a full ground plane layer with a radius of $R_{g}$. PDMS

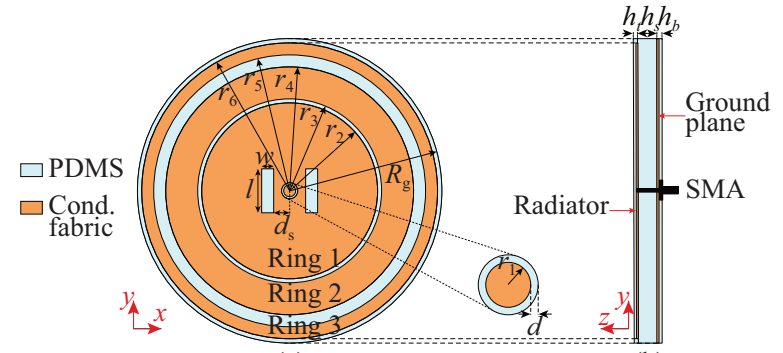

(a)

(b)

Fig. 1. Proposed antenna geometry: (a) front view, (b) side view. The final dimensions are $r_{1}=1.5, r_{2}=22, r_{3}=23, r_{4}=31, r_{5}=34, r_{6}=37$, $R_{g}=38, l=11, w=3, d_{s}=4, d=0.5, h_{t}=0.2, h_{s}=5.5$, and $h_{b}=0.2$. All dimensions are in millimeters.

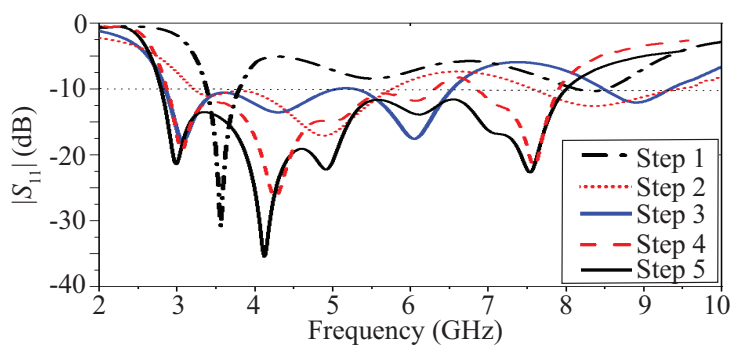

Fig. 2. Simulated $\left|S_{11}\right|$ of the antenna for each design step.

encapsulation layers which completely cover the antenna, were added to provide mechanical robustness and resilience to the structure [21], [25].

The flow of the design process is illustrated by the input reflection coefficient $\left(\left|S_{11}\right|\right)$ results provided in Fig. 2, which is explained as follows. The design strategy is to simultaneously excite and combine a number of $\mathrm{TM}_{0 n}$ resonance modes, for their well-known conical or monopole-like radiation pattern [26], till an ultra-wide bandwidth is achieved. The use of $\mathrm{TM}_{0 n}$ modes is mainly because these modes generally produce a better omnidirectional pattern, particularly in the azimuth plane, with a higher gain compared to when other modes (e.g., $\mathrm{TM}_{21}, \mathrm{TM}_{31}, \mathrm{TM}_{41}$ ) are excited [27], [28].

Step 1: To begin with, an annular-ring circular patch, which is basically a circular patch that couple feeds a ring patch (ring 1), is designed to operate in its $\mathrm{TM}_{01}$ mode at $3.3 \mathrm{GHz}$ (see the black dashed line in Fig. 2). The radius of the annular-ring $\left(r_{2}\right)$ is obtained from the following formula [28],

$$
r_{2}=\frac{k_{01} c}{2 \pi f_{r} \sqrt{\epsilon_{r}}}
$$

where $k_{01}$ is the first root of the n-order Bessel function (i.e., 2.405) and $f_{r}$ is the corresponding resonance frequency of 3.3 $\mathrm{GHz}$. Such structure was chosen as it gives more freedom to achieve different operation bandwidths, for instance through the combination of $r_{2}$, circular patch radius $\left(r_{1}\right)$ or ring slot position, and ring slot gap $(d)$ [23].

Step 2: We also found that by tuning $r_{1}$ and $\mathrm{d}$, the position and matching of other resonances, each corresponding to $\mathrm{TM}_{02}$ and $\mathrm{TM}_{04}$ modes, can be controlled. Those two values were then optimized to bring the $\mathrm{TM}_{02}$ and $\mathrm{TM}_{04}$ resonances to approximately $5 \mathrm{GHz}$, closer to the $\mathrm{TM}_{01}$ resonance, and $8.5 \mathrm{GHz}$, respectively. This antenna $\left|S_{11}\right|$ from this stage is shown by the red dotted line in Fig. 2 .

\section{ACCEPTED MANUSCRIPT}




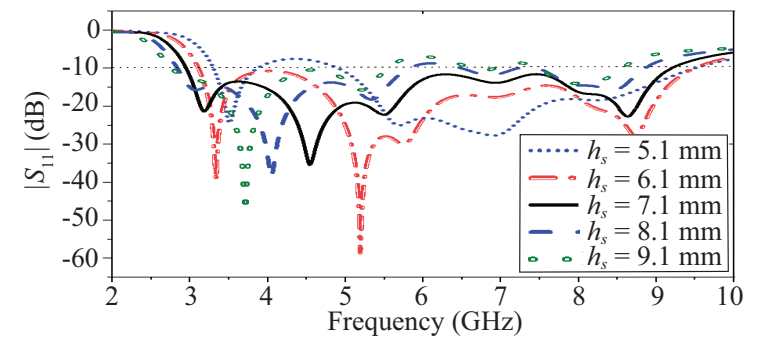

Fig. 3. Simulated $\left|S_{11}\right|$ of the antenna for different substrate thickness $\left(h_{s}\right)$.

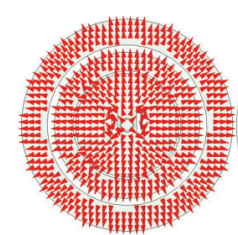

(a)

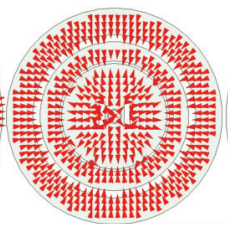

(b)

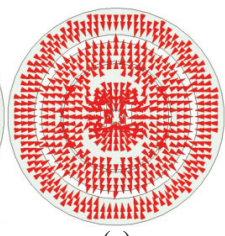

(c)

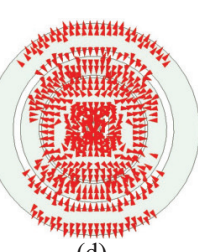

(d)
Fig. 4. Simulated current distribution on the patch surface at (a) $3.3 \mathrm{GHz}$ $\left(\mathrm{TM}_{01}\right)$, (b) $4.5 \mathrm{GHz}\left(\mathrm{TM}_{02}\right)$, (c) $6.8 \mathrm{GHz}\left(\mathrm{TM}_{03}\right)$, and $8.7 \mathrm{GHz}\left(\mathrm{TM}_{04}\right)$.

Step 3: Ring 2, which has an inner and outer radius of $r_{3}$ and $r_{4}$, respectively, was added to the structure. The right coupling between ring 1 and 2, obtained through optimization of the radius and gap among them, were utilized to shift the position of the resonance of the $\mathrm{TM}_{01}$ and $\mathrm{TM}_{02}$ towards the lower frequency band and improves their matching. Concurrently, such a process leads to the shift of the $\mathrm{TM}_{04}$ resonance slightly to higher frequency and generation of another resonance around $6.1 \mathrm{GHz}$ which corresponds to the $\mathrm{TM}_{03}$ mode. This design phase is depicted by the blue solid line in Fig. 2.

Step 4: Following that, two rectangular slots, designed to have a length $(l)$ of approximately $\lambda_{g} / 2$ at $8.7 \mathrm{GHz}$, were added to improve the bandwidth in the higher frequency band. The slots dimensions and placements were optimized to give a minimal effect to the antenna operating modes. As shown by the red dashed line in Fig. 2, the inclusion of the optimized slots significantly improves the matching not only in the upperfrequency band, but also in the lower frequency band.

Step 5: Finally, for further improvement of the antenna impedance matching throughout the whole operating band, the antenna was loaded with another ring patch (ring 3) having inner and outer radii of $r_{5}$ and $r_{6}$, respectively. The $\left|S_{11}\right|$ of the antenna after this final step is shown by the black solid line in Fig. 2.

Optimization of the antenna design parameters was further conducted in CST Microwave Studio 2017. This includes the thickness of the antenna substrate $\left(h_{s}\right)$, whose effect particularly to the antenna return loss is quite significant as shown in Fig. 3. The effects of the encapsulation layers on the performance of the antenna were also investigated. We found that the bottom encapsulation layer does not have any impact on the antenna performance, whereas the top encapsulation layer causes a $120 \mathrm{MHz}$ downshift in the frequency, due to a decrease in the guided wavelength. The effect in terms of gain is also insignificant as the thickness of the top encapsulation is very thin. The optimum dimensions of the antenna are given in the caption of Fig. 1. The surface current distribution of the antenna at four different frequencies, 3.3, 4.5, 6.8, and

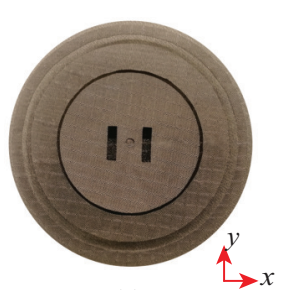

(a)

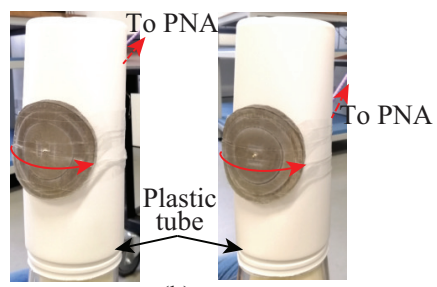

(b)
Fig. 5. (a) Photograph of the fabricated UWB antenna. (b) Bending experimental setups over a plastic tube having outer radius of $40 \mathrm{~mm}$ : Case 1 (left): antenna was bent around its $x$-axis; Case 2 (right): antenna was bent around its $y$-axis.

8.7 GHz, are given in Fig. 4, which show the corresponding $\mathrm{TM}_{01}, \mathrm{TM}_{02}, \mathrm{TM}_{03}$ and $\mathrm{TM}_{04}$ operating modes, respectively. From the current patterns, it can be inferred that the antenna produces fields that vary along with the radial directions but are independent of the azimuth angle $(\phi)$. As a result, monopole-like radiations are generated throughout the whole operating band.

\section{B. Antenna Prototype}

The prototype fabrication was done through a layer-bylayer assembly process starting from the bottom to the top encapsulation layers which completely cover the antenna [25]. Each layer of the structure was prepared in the mold by adding liquid PDMS to achieve required thicknesses, and curing to achieve solidification. Pattern of the conductive elements cut out of the conductive fabric manually, were added at requisite thicknesses of PDMS. Two different conductive fabrics are utilized for patch and ground parts of the antenna. Conductive fabric with higher conductivity, i.e., nickel-copper-silvercoated nylon ripstop from Marktek Inc., having a thickness of $0.13 \mathrm{~mm}$ was employed for the patches of the antenna. Concurrently, a nickel-copper coated ripstop from Less EMF Inc., having a thickness of $0.08 \mathrm{~mm}$ was utilized for the ground. While still having an acceptable conductivity, the second fabric has a higher porosity than the first one which is beneficial for better PDMS and fabric attachment over a large surface. Conductivity values after taking into account the PDMS percolation inside the fabric pores, $1.02 \times 10^{5} \mathrm{~S} / \mathrm{m}$ and $5.4 \times 10^{4} \mathrm{~S} / \mathrm{m}$, were applied during the simulations to model the composite of PDMS with first and second fabrics, respectively [25]. The fabricated prototype is shown in Fig. 5(a).

\section{Antenna Performance And Discussion}

\section{A. Input Impedance}

The $\left|S_{11}\right|$ of the fabricated prototype was measured using Agilent PNA-X N5242A network analyzer and is shown in Fig. 6, alongside numerically computed results from CST Microwave Studio. As can be seen in Fig. 6(a), the measured result follows a very similar trend with the simulation despite the resonance at a higher frequency, around $8.6 \mathrm{GHz}$, that shifts down to $7.5 \mathrm{GHz}$. This results in a $10 \mathrm{~dB}$ return loss bandwidth of the antenna ranging from 2.85 to $8.6 \mathrm{GHz}$, which is slightly smaller than that predicted from simulations, i.e., from 2.95 to $9.2 \mathrm{GHz}$. The higher frequency end of the operating bandwidth is sensitive to the dimension and placement of the rectangular slot, as discussed in Section II.

\section{ACCEPTED MANUSCRIPT}




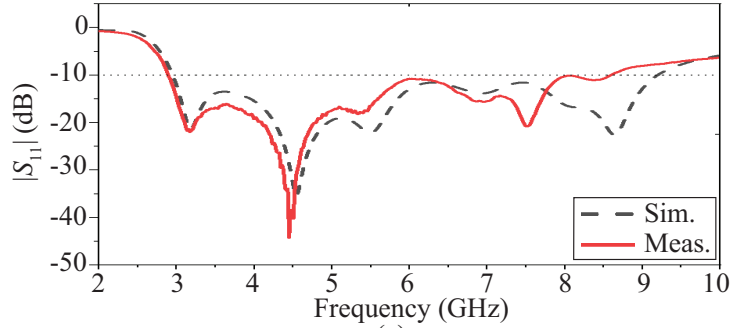

(a)

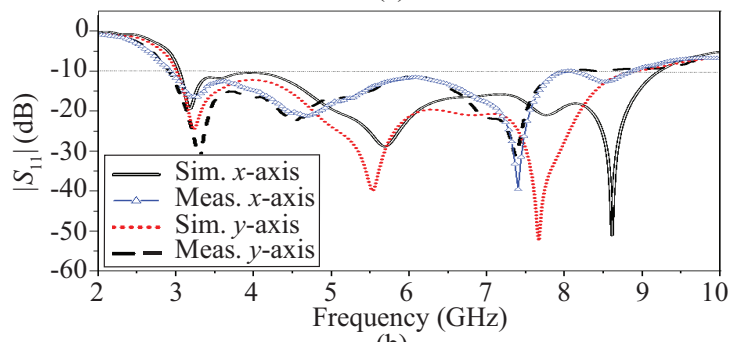

(b)

Fig. 6. Comparison between simulated and measured $\left|S_{11}\right|$ of the proposed antenna: (a) in flat form, (b) under $x$-axis and $y$-axis bendings $\left(r_{b}=40 \mathrm{~mm}\right)$.

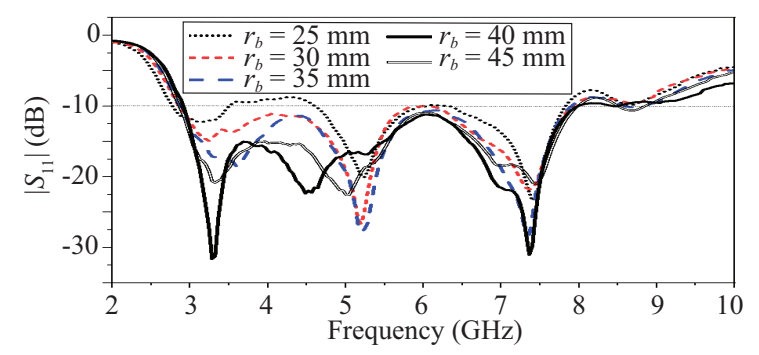

Fig. 7. Measured $\left|S_{11}\right|$ of the proposed antenna bent around tubes with different radii.

Manual handling of the conductive fabric and PDMS encapsulation process introduce minute fabrication inaccuracies in the placement and separation between ring 1, ring 2 and ring 3 , causing for this reduction.

To verify the conformability of the antenna, antenna bending experiments were carried out. Firstly, the antenna prototype was bent over a hollow plastic tube having a radius $\left(r_{b}\right)$ of $40 \mathrm{~mm}$ and its $S_{11}$ was measured. The bending was applied in two scenarios, around $x$ - and $y$-axis, and tape was used to maintain the position of the antenna on the tube during the measurement (see Fig. 5(b)). Fig. 6(b) shows the corresponding $\left|S_{11}\right|$ results which we compared with those from simulations. In both results, it is shown that the return loss is still maintained above $10 \mathrm{~dB}$ across the operating band, validating the antenna's robustness against physical deformation. Secondly, for further verification, the antenna was bent over tubes with various radii, representing varying level of bending from moderate to severe. In this case, the bendings were only done along the $y$-axis considering the similar response shown in previous experiment. The measured $\left|S_{11}\right|$ of the antenna is given in Fig. 7 demonstrating the capability of the antenna to maintain an acceptable level of return loss even up to the bending radius of $30 \mathrm{~mm}$. Most importantly, we observed that the antenna did not break and can still return to its shape after bending, owing to the flexibility and robustness of PDMSconductive fabric composite. Similar $\left|S_{11}\right|$ result was also
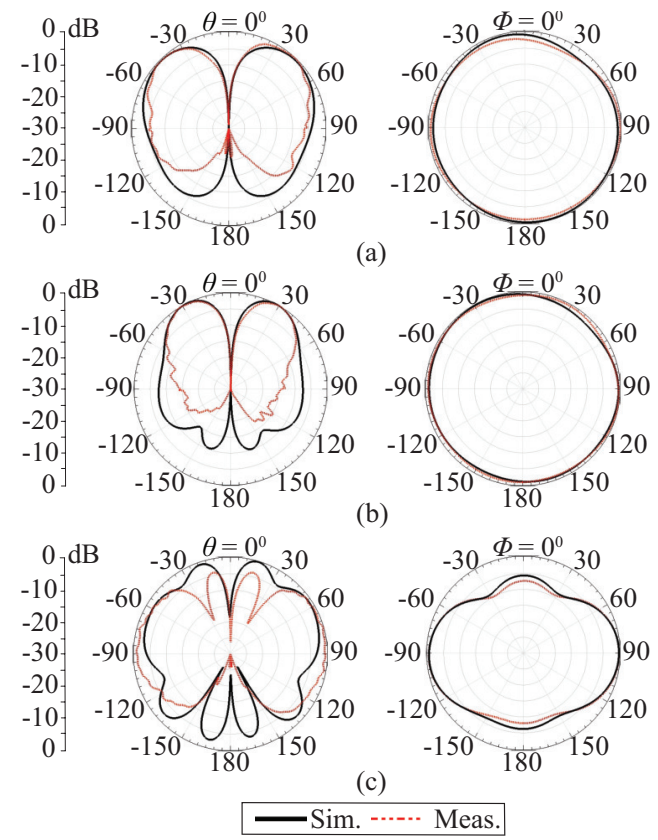

Fig. 8. Measured (dotted line) and simulated (solid line) normalized radiation patterns of the proposed antenna in $x z$-plane (left side) and $x y$-plane (right side) at: (a) $3.3 \mathrm{GHz}$, (b) $5.6 \mathrm{GHz}$, and (c) $7.8 \mathrm{GHz}$.

noticed every time the antenna was brought to its initial shape after each bending, which suggests the performance stability of the proposed antenna.

\section{B. Far-Field Characteristics}

Far-field patterns of the proposed antenna obtained from NSI700S-50 spherical near-field anechoic chamber at the Australian Antenna Measurement Facility (AusAMF) are shown in Fig. 8. The results are compared with those from simulations at selected frequencies of $3.3,5.6$, and $7.8 \mathrm{GHz}$. The antenna produces radiation characteristics resemble those of a monopole antenna, omnidirectional in $x y$-plane and fairly bidirectional in $x z$-plane. Notably, such characteristics are maintained over the entire operating band and they agree well with the simulated results. The antenna peak gain varying between 2.9 to $6.2 \mathrm{dBi}$ was obtained from the measurement with radiation efficiency as shown in Fig. 9, calculated from measured directivity and gain of the antenna. The decreasing efficiency of the antenna is due to the increase of loss of the material used, particularly the PDMS as shown in Fig. 9.

The gain of monopolar patch antennas, such as the one proposed here, depends not only on the frequency but also the direction of observation. In the Impulse Radio (IR) regime, such as in UWB communications, the full instantaneous bandwidth is utilised for communications, and therefore, resorting to Mean Realized Gain (MRG), as defined in [29]-[33], provides a more complete view of the antenna performance. The MRG of the proposed antenna, computed by averaging the measured realized gain of the antenna at a given direction across the whole operating bandwidth, is shown in Fig. 10 for $x z$ and $y z$ planes. It can be noted that the MRG shows monopole-like patterns, suggesting that monopolar radiation characteristic is indeed maintained by the antenna over the entire operating bandwidth.

\section{ACCEPTED MANUSCRIPT}




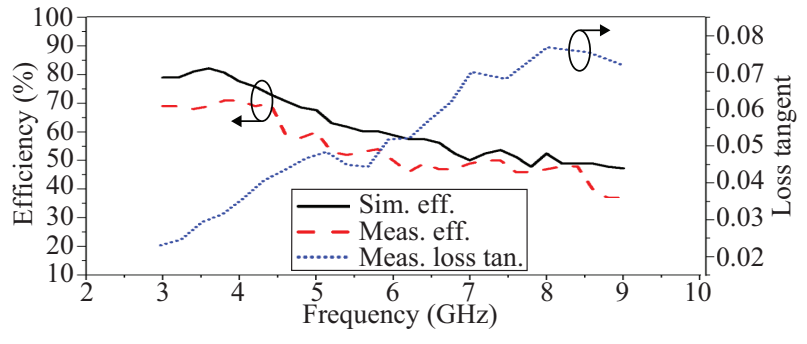

Fig. 9. Measured and simulated radiation efficiency of the proposed antenna.

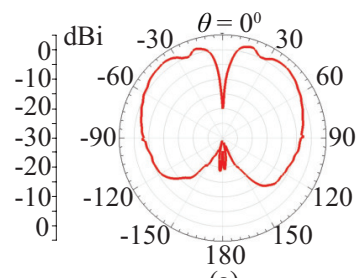

(a)

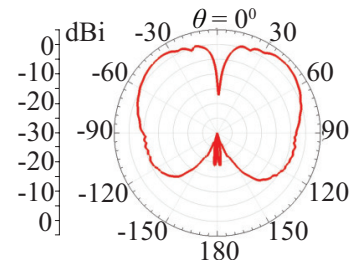

(b)
Fig. 10. Measured MRG of the proposed antenna in: (a) $x z$ and (b) $y z$ planes.

\section{C. $S F F$}

Typically, ordinary wideband antennas are not capable of transmitting short pulses because they radiate different frequency components from different parts of the antenna, hence the transmitted pulse is stretched out/distorted. Understanding this, we conducted an SFF analysis of our proposed antenna to evaluate its capability for UWB pulse transmission [34], [35]. We used SFF to take into account the distortion induced by both the transmitting (Tx) and receiving (Rx) antennas. To do that, we simulated two identical antennas in CST Microwave Studio 2017, positioned in line with a distance of $300 \mathrm{~mm}$ as illustrated in Fig. 11(a), and obtained the transmission coefficient $\left(S_{21}\right)$. A Gaussian pulse with a spectrum corresponding to the bandwidth of the antenna $(2.95-9.2 \mathrm{GHz})$ was generated as the input signal. By post-processing the input signal with the transfer function of the two-antenna system $\left(S_{21}\right)$, the received pulse was obtained. The latter was then cross-correlated with the input signal to get the SFF values.

To get a complete performance of the antenna, we repeated this process across the whole azimuthal angle by rotating $\mathrm{Rx}$ every $15^{\circ}$ in the $x y$-plane while keeping Tx stationary. We also conducted this time-domain investigation for the case where both antennas were conformed, along $x$ - and $y$-axis, with a bending radius of $40 \mathrm{~mm}$ (see Fig. 11(a)). The SFF results for all three cases are given in Fig. 11(b), shown only from $\phi=0^{\circ}$ to $180^{\circ}$, considering the symmetrical radiation characteristics of the antenna, hence the SFF values. As can be seen, the antenna achieves the SFF more than $86 \%$ which are higher than the accepted SFF of 50\% [34], thus validating its capability in preserving the pulse shape and suitability of the proposed antenna for UWB pulse transmission.

Table I shows the properties of the proposed antenna in comparison with the other presented UWB monopole-like pattern antennas and wideband circular patch antennas. The proposed structure shows an acceptable compromising between the size, height and gain of the antenna. Moreover, while other presented works are based on rigid structures, the proposed work is fabricated using the flexible PDMS-

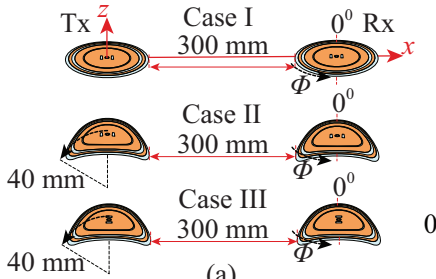

(a)

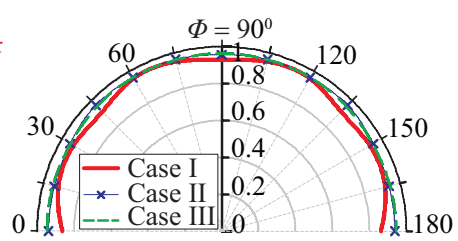

(b)
Fig. 11. (a) SFF analysis setups for the cases when both antennas are flat (Case I), bent along $x$-axis (Case II), and bent along $y$-axis (Case III). (b) System fidelity patterns in horizontal plane obtained from simulations.

conductive fabric composite showing measured efficiency of higher than $45 \%$ for the entire bandwidth. In addition, it does not need any extra protection (e.g., radome), matching circuits and complex feeding networks.

\section{CONCLUSION}

In this paper, we have successfully demonstrated for the first time a conformal UWB antenna with radiation characteristics resemble a vertically-polarized monopole antenna. Such characteristic was achieved by exciting and combining four operating modes, $\mathrm{TM}_{01}, \mathrm{TM}_{02}, \mathrm{TM}_{03}$, and $\mathrm{TM}_{04}$, of an annular-rings loaded circular patch antenna, making the design is completely planar, unlike previously published work in this area. The proposed antenna was fabricated using PDMSconductive fabric composite material, thus suitable for conformal applications, validated through various bending tests. The time-domain analysis also demonstrated that the antenna in either conditions, flat or bent, is suitable for UWB pulse transmission, justified through SFF values of more $86 \%$ for a Gaussian pulse having a spectrum from 2.95 to $9.2 \mathrm{GHz}$.

\section{REFERENCES}

[1] J. Foerster, E. Green, S. Somayazulu, D. Leeper, I. A. Labs, I. A. Labs, I. Corp, and I. Corp, "Ultra-wideband technology for short-or mediumrange wireless communications," Intel Tech. Journal, vol. 2, pp. 1-11, 2011.

[2] A. Fort, C. Desset, P. De Doncker, P. Wambacq, and L. Van Biesen, "An ultra-wideband body area propagation channel model-from statistics to implementation," IEEE Trans. Microw. Theory Techn., vol. 54, no. 4, pp. 1820-1826, 2006.

[3] J. Zhang, P. V. Orlik, Z. Sahinoglu, A. F. Molisch, and P. Kinney, "UWB systems for wireless sensor networks," Proc. IEEE, vol. 97, no. 2, pp. 313-331, 2009.

[4] A. Elsherbini and K. Sarabandi, "Very low-profile top-loaded UWB coupled sectorial loops antenna," IEEE Antennas Wireless Propag. Lett., vol. 10 , pp. 800-803, 2011.

[5] D. W. Aten and R. L. Haupt, "A wideband, low profile, shorted top hat monocone antenna," IEEE Trans. Antennas Propag., vol. 60, no. 10, pp. 4485-4491, 2012.

[6] G. Adamiuk, T. Zwick, and W. Wiesbeck, "UWB antennas for communication systems," Proc. IEEE, vol. 100, no. 7, pp. 2308-2321, 2012.

[7] N. Behdad, M. Li, and Y. Yusuf, "A very low-profile, omnidirectional, ultrawideband antenna," IEEE Antennas Wireless Propag. Lett., vol. 12, pp. 280-283, 2013.

[8] M. Koohestani, J.-F. Zürcher, A. A. Moreira, and A. K. Skrivervik, "A novel, low-profile, vertically-polarized UWB antenna for WBAN," IEEE Trans. Antennas Propag., vol. 62, no. 4, pp. 1888-1894, 2014.

[9] Y. Li, X.-D. Yang, C.-Y. Liu, and T. Jiang, "A sleeve monopole antenna with wide impedance bandwidth for indoor base station applications," Prog. In Electromagnetics Research C, vol. 16, pp. 223-232, 2010.

[10] B. Mohamadzade and A. Rezaee, "Compact and broadband dual sleeve monopole antenna for GSM, WiMAX and WLAN application," Microw. and Opt. Tech. Letters, vol. 59, no. 6, pp. 1271-1277, 2017.

[11] M. Ammann and Z. N. Chen, "Wideband monopole antennas for multiband wireless systems," IEEE Antennas Propag. Mag., vol. 45, no. 2, pp. 146-150, 2003. 
TABLE I

COMPARISON WITH PREVIOUSLY REPORTED ANTENNAS

\begin{tabular}{|c|c|c|c|c|c|c|c|c|}
\hline Antenna & Structure & $\stackrel{\text { Size }}{\left(\lambda_{\min } \times \lambda_{\min }\right)}$ & $\begin{array}{l}\text { Height } \\
\left(\lambda_{\min }\right)\end{array}$ & $\begin{array}{l}\text { Volume } \\
\left(\lambda_{\text {min }}^{3}\right)\end{array}$ & $\begin{array}{l}\text { Gain } \\
(\mathrm{dBi})\end{array}$ & $\begin{array}{l}\text { Bandwidth } \\
\text { (GHz) }\end{array}$ & $\begin{array}{l}\text { Suitability } \\
\text { for } \\
\text { bending }\end{array}$ & $\begin{array}{c}\text { Radome/ } \\
\text { complex feeding/ } \\
\text { matching circuit/ } \\
\text { delicate parts }\end{array}$ \\
\hline $\begin{array}{l}\text { This } \\
\text { work }\end{array}$ & $\begin{array}{l}\text { Ring patches loaded } \\
\text { circular patch }\end{array}$ & $0.72 \times 0.72$ & 0.067 & 0.035 & 2.9 to 6.2 & 2.85 to 8.6 & Yes & No \\
\hline [4] & Top-hat loaded loops & $0.9 \times 0.9$ & 0.053 & 0.043 & NA & 0.9 to 6 & No & $\begin{array}{c}\text { Yes (thin shorting } \\
\text { legs) }\end{array}$ \\
\hline [7] & Top-hat loaded loops & $0.22 \times 0.22$ & 0.033 & 0.001 & 2.5 to 8 & 1 to 4 & No & Yes (feed network) \\
\hline$[8]$ & Top-hat loaded monocone & $0.65 \times 0.65$ & 0.086 & 0.036 & NA & 3.06 to 12 & No & $\begin{array}{l}\text { Yes (thin shorting } \\
\text { legs and radome) }\end{array}$ \\
\hline [14] & Loops & $1.36 \times 1.36$ & 0.16 & 0.026 & -5 to 7 & 2.05 to 15.3 & No & No \\
\hline [15] & $\begin{array}{l}\text { Ring-patch loaded } \\
\text { monocone }\end{array}$ & $0.64 \times 0.64$ & 0.07 & 0.028 & $\begin{array}{l}2.04(\text { at } 3.2 \mathrm{GHz}), \\
4.5(\text { at } 5.6 \mathrm{GHz}), \\
6.41(\text { at } 7.8 \mathrm{GHz})\end{array}$ & 2.8 to 11.4 & No & $\begin{array}{l}\text { Yes (thin shorting } \\
\text { pins) }\end{array}$ \\
\hline [16] & Top-hat loaded loops & $0.26 \times 0.26$ & 0.046 & 0.003 & 4 to 7.5 & 0.66 to 5.6 & No & $\begin{array}{l}\text { Yes (matching } \\
\text { network) }\end{array}$ \\
\hline [17] & Top-hat loaded loops & $0.14 \times 0.14$ & 0.09 & 0.0017 & 6.5 to 8.7 & 0.69 to 2.84 & No & Yes (feed network) \\
\hline [18] & $\begin{array}{l}\text { Top-hat loaded monocone } \\
\text { and loops }\end{array}$ & $0.8 \times 0.8$ & 0.25 & 0.016 & 0 to 7.5 & 0.6 to 1.75 & No & $\begin{array}{l}\text { Yes (feed network, } \\
\text { thin long feeding } \\
\text { strip) }\end{array}$ \\
\hline [22] & $\begin{array}{l}\text { Ring patch loaded } \\
\text { circular patch }\end{array}$ & $2.18 \times 2.18$ & 0.027 & 0.128 & 3 to 6 & 5.45 to 7.16 & No & No \\
\hline [23] & $\begin{array}{l}\text { Ring patches loaded } \\
\text { circular patch }\end{array}$ & $2.85 \times 2.85$ & 0.029 & 0.22 & $\begin{array}{c}5.7 \text { at } 5.8 \mathrm{GHz} \\
\text { (Sim.) }\end{array}$ & 5.7 to 6.48 & No & No \\
\hline [24] & $\begin{array}{l}\text { Ring patch loaded } \\
\text { circular patch }\end{array}$ & $0.85 \times 0.85$ & 0.071 & 0.051 & 2.6 to 6.4 & 4.27 to 8.72 & No & $\begin{array}{l}\text { Yes (thin shorting } \\
\text { pins) }\end{array}$ \\
\hline
\end{tabular}

[12] J. W. Lee, C. S. Cho, and J. Kim, "A new vertical half disc-loaded ultrawideband monopole antenna (VHDMA) with a horizontally top-loaded small disc," IEEE Antennas Wireless Propag. Lett., vol. 4, pp. 198-201, 2005.

[13] M. Lapierre, Y. M. Antar, A. Ittipiboon, and A. Petosa, "Ultra wideband monopole/dielectric resonator antenna," IEEE Microw. Compon. Lett., vol. 15 , no. 1 , pp. $7-9,2005$

[14] N. Behdad and K. Sarabandi, "A compact antenna for ultrawide-band applications," IEEE Trans. Antennas Propag., vol. 53, no. 7, pp. 21852192,2005

[15] W. Jeong, J. Tak, and J. Choi, "A low-profile IR-UWB antenna with ring patch for WBAN applications," IEEE Antennas Wireless Propag. Lett., vol. 14, pp. 1447-1450, 2015.

[16] K. Ghaemi and N. Behdad, "A low-profile, vertically polarized ultrawideband antenna with monopole-like radiation characteristics," IEEE Trans. Antennas Propag., vol. 63, no. 8, pp. 3699-3705, 2015.

[17] M. Li and N. Behdad, "A compact, capacitively fed UWB antenna with monopole-like radiation characteristics," IEEE Trans. Antennas Propag., vol. 65, no. 3, pp. 1026-1037, 2017.

[18] R. Lian, T.-Y. Shih, Y. Yin, and N. Behdad, "A high-isolation, ultrawideband simultaneous transmit and receive antenna with monopole-like radiation characteristics," IEEE Trans. Antennas Propag., vol. 66, no. 2, pp. 1002-1007, 2018.

[19] S. Nikolaou, G. E. Ponchak, J. Papapolymerou, and M. M. Tentzeris, "Conformal double exponentially tapered slot antenna (DETSA) on LCP for UWB applications," IEEE Trans. Antennas Propag., vol. 54, no. 6, pp. 1663-1669, 2006.

[20] G. H. Huff and J. J. McDonald, "A spherical inverted-F antenna (SIFA)," IEEE Antennas Wireless Propag. Lett., vol. 8, pp. 649-652, 2009.

[21] B. Mohamadzade, R. M. Hashmi, R. B. V. B. Simorangkir, R. Gharaei, S. Ur Rehman, and Q. H. Abbasi, "Recent advances in fabrication methods for flexible antennas in wearable devices: State of the art," Sensors, vol. 19, no. 10, p. 2312, 2019.

[22] Y. Zhang, J. Liu, Z. Liang, and Y. Long, "A wide-bandwidth monopolar patch antenna with dual-ring couplers," Int. Journal of Ant. and Propag., vol. 2014, 2014

[23] A. Al-Zoubi, F. Yang, and A. Kishk, "A broadband center-fed circular patch-ring antenna with a monopole like radiation pattern," IEEE Trans. Antennas Propag., vol. 57, no. 3, pp. 789-792, 2009.

[24] S.-F. Zheng, Y.-Z. Yin, X.-S. Ren, Z.-Y. Liu, and L. Kang, “A wideband low-profile monopolar patch antenna," Micro. and Opt. Tech. Letters, vol. 53, no. 1, pp. 28-32, 2011.

[25] R. B. V. B. Simorangkir, Y. Yang, R. M. Hashmi, T. Björninen, K. P. Esselle, and L. Ukkonen, "Polydimethylsiloxane-embedded conductive fabric: Characterization and application for realization of robust passive and active flexible wearable antennas," IEEE Access, vol. 6, pp. 48102 48 112, 2018.

[26] R. Garg, R. Bhartia, I. Bahl, and A. Ittipiboon, "Circular disk and ring antennas," in Microstrip Antenna Design Handbook. Boston: Artech House, Inc., 2001, ch. 5, pp. 317-398.

[27] J. Tak and J. Choi, "Circular-ring patch antenna with higher order mode for on-body communications," Microw. and Opt. Tech. Letters, vol. 56, no. 7, pp. 1543-1547, 2014.

[28] S. Liu, W. Wu, and D.-G. Fang, "Wideband monopole-like radiation pattern circular patch antenna with high gain and low cross-polarization," IEEE Trans. Antennas Propag., vol. 64, no. 5, pp. 2042-2045, 2016.

[29] C. Roblin, "Representation, characterization and modeling of ultra wide band antennas," in Ultra Wide Band Antennas, X. Begaud, Ed. New York, USA: ISTE/WILEY, 2011, ch. 3, pp. 61-112.

[30] C. Roblin, "Ultra compressed parametric modelling of UWB antenna measurements," in Proc. $1^{\text {st }}$ Eur. Conf. on Ant. and Propag. (EuCAP), 2006, pp. 1-8.

[31] C. Roblin, J.-M. Laheurte, R. D'Errico, A. Gati, D. Lautru, T. Alvès, H. Terchoune, and F. Bouttout, "Antenna design and channel modeling in the BAN context-Part I: Antennas," Annals of Telecommunicationsannales des télécommunications, vol. 66, no. 3, pp. 139-155, 2011.

[32] R. D'Errico, H. Ghannoum, C. Roblin, and A. Sibille, "Small semi directional antenna for UWB terminal applications," in Proc. $1^{\text {st }}$ Eur. Conf. on Ant. and Propag. (EuCAP), 2006, pp. 1-6.

[33] Y.-f. Wei and C. Roblin, "Multislot antenna with a screening backplane for UWB WBAN applications," Int. Journal of Ant. and Propag., vol. 2012, no. 731912, 2012.

[34] G. Quintero, J.-F. Zurcher, and A. K. Skrivervik, "System fidelity factor: A new method for comparing UWB antennas," IEEE Trans. Antennas Propag., vol. 59, no. 7, pp. 2502-2512, 2011.

[35] R. B. V. B. Simorangkir, A. Kiourti, and K. P. Esselle, "UWB wearable antenna with a full ground plane based on PDMS-embedded conductive fabric," IEEE Antennas Wireless Propag. Lett., vol. 17, no. 3, pp. 493496, 2018. 